\section{Propuesta para una distribución equitativa de recursos en el nordeste de México}

Los cambios en el perfil de las poblaciones han obligado a los sistemas de salud a buscar cómo hacer frente a nuevos problemas. Una esperanza de vida más larga ha resultado en el envejecimiento de multitudes y los cambios en los estilos de vida y factores de riesgo han contribuido al surgimiento de enfermedades nuevas. Cada día se vuelve más apremiante distribuir equitativamente los limitados fondos disponibles para cubrir las necesidades de la población. Aunque se está haciendo un esfuerzo constante para satisfacerlas y lograr salud para todos con eficiencia, calidad y equidad, se observan grandes diferencias en las necesidades de salud y en la respuesta social organizada en grupos de población.

El estudio que aquí se resume enfoca la búsqueda de áreas donde las diferentes necesidades de salud existen como un modelo vertical de equidad, con objeto de dar prioridad adecuada a las acciones destinadas a una zona en particular en consideración de la escasez de recursos. Se llama la atención a estudios realizados en Suráfrica, Colombia, Chile y Brasil cuyos resultados se han presentado en foros internacionales en el seno de la OMS. En otros estudios se ha procurado determinar la cobertura y distribución de los servicios de salud y su relación con la pobreza y la condición social. En México es importante medir el efecto de las reformas adoptadas, actividad impulsada por un grupo de acopio y análisis de información e iniciativas de reforma (NAADIIR) para los servicios de salud, el cual depende del Instituto Nacional de Salud Pública y colabora con la OMS. En fin, se han planteado muchas vías de investigación y diversas fórmulas de distribución de recursos basadas en diferentes indicadores. El trabajo prioritario consiste en proponer un método adecuado para determinar el grado de equidad que permita distribuir los recursos según los requisitos de salud.

De acuerdo con esa idea, se realizó un estudio ecológico en una institución de seguridad social que en el nordeste abarca los estados de Nuevo León, Coahuila y Tamaulipas. La institución tiene una red de servicios que debe responder a las necesidades de salud de la población y coordinar los recursos disponibles para atender a las personas con vínculos de trabajo formales y a sus familias. Las delegaciones estatales están formadas por 17 áreas médicas de gestión desconcentrada (AMGD), cada una con un hospital de atención secundaria y un grupo de unidades médicas de atención primaria.

El grado de equidad se midió de acuerdo con la concordancia entre la posición de cada AMGD con respecto a las necesidades de salud y su posición en cuanto a gastos per cápita; mientras más alta la concordancia, más alta la equidad. Las necesidades de salud se determinaron siguiendo un índice general basado en indicadores propuestos por la OMS: uso de la atención de salud preventiva, incluido el porcentaje de derechohabientes $(\mathrm{DH})$ de edad reproductiva que emplean algún método de planificación familiar; porcentaje de niños y adultos que han recibido algún tipo de inmunización; adultos con diagnóstico de tuberculosis pulmonar, diabetes mellitus, hipertensión arterial, cáncer cervicouterino, sífilis e infección por VIH en el departamento de medicina preventiva, y porcentaje de embarazadas que reciben atención prenatal. El índice general también incluye indicadores de recursos materiales, como el número de oficinas, camas, unidades de laboratorio para el examen de muestras y salas de radiología (por $1000 \mathrm{DH}$ ), así como el estado de salud basado en años de vida saludables por $1000 \mathrm{DH}$ en relación con las 10 principales causas de muerte. Estos indicadores se usaron para organizar las necesidades de salud de cada AMGD en una jerarquía mediante la creación de una base de datos que sirvió para calcular el índice $Z$ de cada área. Luego las AMGD se ordenaron de forma ascendente. (Los índices $Z$ negativos son valores alejados de la media e indican mayores necesidades.)

Para los gastos por atención médica se usó el indicador de distribución anual de recursos financieros por $\mathrm{DH}$ y se consideraron los rubros siguientes del presupuesto: salarios, medicamentos, material sanitario, alimentos, ropa, suministros de oficina, combustible y lubricantes; muebles y equipo pequeño; mantenimiento y reparaciones, alquiler, boletos y estipendio para gastos diarios, electricidad y comunicaciones, y servicios de subrogación proporcionados por la institución de salud y distribuidos a cada área. Por último, las AMGD se clasificaron en orden de mayores a menores necesidades, se determinó su posición en gastos por atención médica y se determinó el coeficiente de concordancia de Kendall.

Las áreas con mayores necesidades del índice general fueron la AMGD 12 de Tamaulipas, con un índice $Z$ de -5 y la 3 de Coahuila, con uno de -4 . Estas áreas tienen varias unidades de salud rurales 
cuya cobertura ha sido más bien escasa debido a la falta de una política de salud consecuente y de un sistema integral y a las limitaciones de la capacidad gerencial. También mostraron necesidades relativamente amplias las áreas 9 de Nuevo León, y 16 y 17 en Tamaulipas, con -2 .

Con respecto a los indicadores del uso de los servicios, las AMGD 12 y 14 en Tamaulipas y la 3 en Coahuila fueron las menos usadas para atención preventiva con $-4,-3$ y -2 , respectivamente. En esas áreas, la población acude a otras instituciones del sector para la detección de enfermedades y la planificación familiar.

La distribución de recursos materiales para la atención de salud fue muy variada. Las AMGD con menos recursos fueron la 17 en Tamaulipas y las 1 y 4 en Coahuila, con índices $Z$ de $-4,-3$ y -2 , respectivamente. La 17 está en una zona fronteriza donde hay diferentes industrias de ensamblaje y la asignación de trabajadores a las unidades médicas de familia es esporádica, lo que hace difícil estimar la respuesta a esa necesidad. En relación con ello se detectan otras faltas de equidad, como un número dispar de unidades de laboratorio y salas de radiología. En este caso, las áreas más necesitadas fueron la número 4 y otras de Coahuila. Sin embargo, si se considera que en México el estándar es de 0,10 unidades de laboratorio por $1000 \mathrm{DH}$ y el de salas de radiología de 0,26 por $1000 \mathrm{DH}$, casi todas las áreas eran deficientes. Con respecto a las camas disponibles, la AMGD 8 en Nuevo León fue la más afectada, con 0,28 camas por $1000 \mathrm{DH}$, cifra mucho más baja que la del país en general (1,2 por 1000 habitantes). Países como el Canadá cuentan con 5,8 camas por 1000 habitantes, pero aun países en desarrollo como Haití tienen por lo menos 1,5 camas por 1000 . Por otro lado, las áreas de Tamaulipas resultaron deficientes en la disponibilidad de consultorios, comparadas con las de Nuevo León.

En cuanto al estado de salud, las AMGD más afectadas fueron la 9 en Nuevo León con un índice $Z$ de -3; la 12 en Tamaulipas con -2; y la 14 en Tamaulipas con -1 . Estos índices pueden considerarse el resultado de necesidades no satisfechas, especialmente en áreas rurales, y superaron aun los años de vida saludable perdidos en los estados de Chiapas, Guerrero y Puebla, donde existe la mayor marginación. Esto revela que las desigualdades pueden estar enmascaradas en lugares pequeños.

La mayor atención de salud per cápita correspondió a la AMGD 12 en Tamaulipas, con una dotación de US\$ 168,90, seguida de la 13 en Tamaulipas, $(\$ 164,35)$ y la 2 de Coahuila $(\$ 146,45)$. Las más necesitadas fueron varias áreas de Nuevo León y la 17 de Tamaulipas. Nuevo León es un estado receptor con una alta inmigración de Tamaulipas, San Luis Potosí, Coahuila y Zacatecas, lo cual genera desequilibrios de diversa magnitud incluso en la salud por falta de datos fidedignos para proyeccio- nes de población. De acuerdo con los gastos en servicios, la AMGD 9 de Nuevo León estaba en tercera posición según las necesidades de salud; pero en gastos per cápita, su decimosegunda posición reflejaba la falta de equidad en ese rubro. La misma falta de concordancia se reveló en las AMGD 17 y 16 de Tamaulipas, 4 de Coahuila y 8 de Nuevo León. Por contraste, la AMGD 2 de Coahuila presentó la mejor condición según las necesidades de salud y una posición privilegiada en cuanto a gastos por atención médica.

En Nuevo León, Coahuila y Tamaulipas se está poniendo en efecto una reforma basada en la descentralización. Se espera que el desarrollo regional y establecimiento ulterior de las AMGD resuelva las crisis relacionadas con el aumento de los costos, y la falta de eficiencia y equidad. La distribución de recursos tiene que responder a las necesidades de cada estado de la región. Se proyecta establecer un sistema de información geográfica adaptable a cualquier ambiente y usar los indicadores que resulten de este trabajo. Se podrían así registrar los cambios estructurales de la población. Esta propuesta, insisten los autores, puede aplicarse a cualquier institución del sector de la salud, siempre que el área geográfica sea pequeña. Como paso inicial, permitiría relacionar la distribución económica con las necesidades de salud, ya que es preciso primero medirlas antes de aplicar el principio de equidad a los recursos.

Será difícil lograr la equidad en situaciones locales mientras no se descentralice la organización y se siga dependiendo de decisiones estratégicas. Además, no se sabe hasta qué punto el sector de la salud podrá liderar el proceso frente a la cultura gerencial. Urge ejecutar políticas dirigidas a lograr la equidad, estimular la participación intersectorial para mejorar la vida y el estado de salud de la población, y realizar la reforma con una perspectiva integral enfocada en las personas y en lograr un desarrollo humano sostenible. (Núñez Rocha GM, et al. Resource allocation equity in northeastern Mexico. Health Pol. 2004; 70:271-9.)

\section{¿Puede omitirse el desayuno sin perjuicio para la salud?}

El efecto del desayuno en las concentraciones de colesterol, triglicéridos, insulina y ácido úrico en la sangre es de continuo interés, por ser su alteración un factor de riesgo de la enfermedad cardiovascular. Según varios estudios, el consumo de desayuno se relaciona de forma negativa con la obesidad. En un ensayo clínico se estratificó al azar a mujeres obesas en un grupo que desayunaba y otro que ayunaba. Las participantes que inicialmente ayunaban perdieron más peso desayunando, mientras que las que antes tomaban desayuno perdieron más peso omi- 